\title{
The balancing act of combining school and football in the transition from a non-professional club into junior-elite academy football
}

\author{
Marius Solhaug ${ }^{1}$, Rune Høigaard ${ }^{1+2}$ \& Stig Arve Sæther ${ }^{1}$ \\ 1 Department of Sociology and Political Science, Norwegian University of Science and Technology, NTNU, Norway \\ ${ }^{2}$ Department of sport and physical education, University of Agder, Norway.
}

Corresponding author: Stig Arve Sæther

E-mail: stigarve@ntnu.no

Department of Sociology and Political Science, Norwegian University of Science and Technology, NTNU

Dragvoll, 7491 Trondheim, Norway

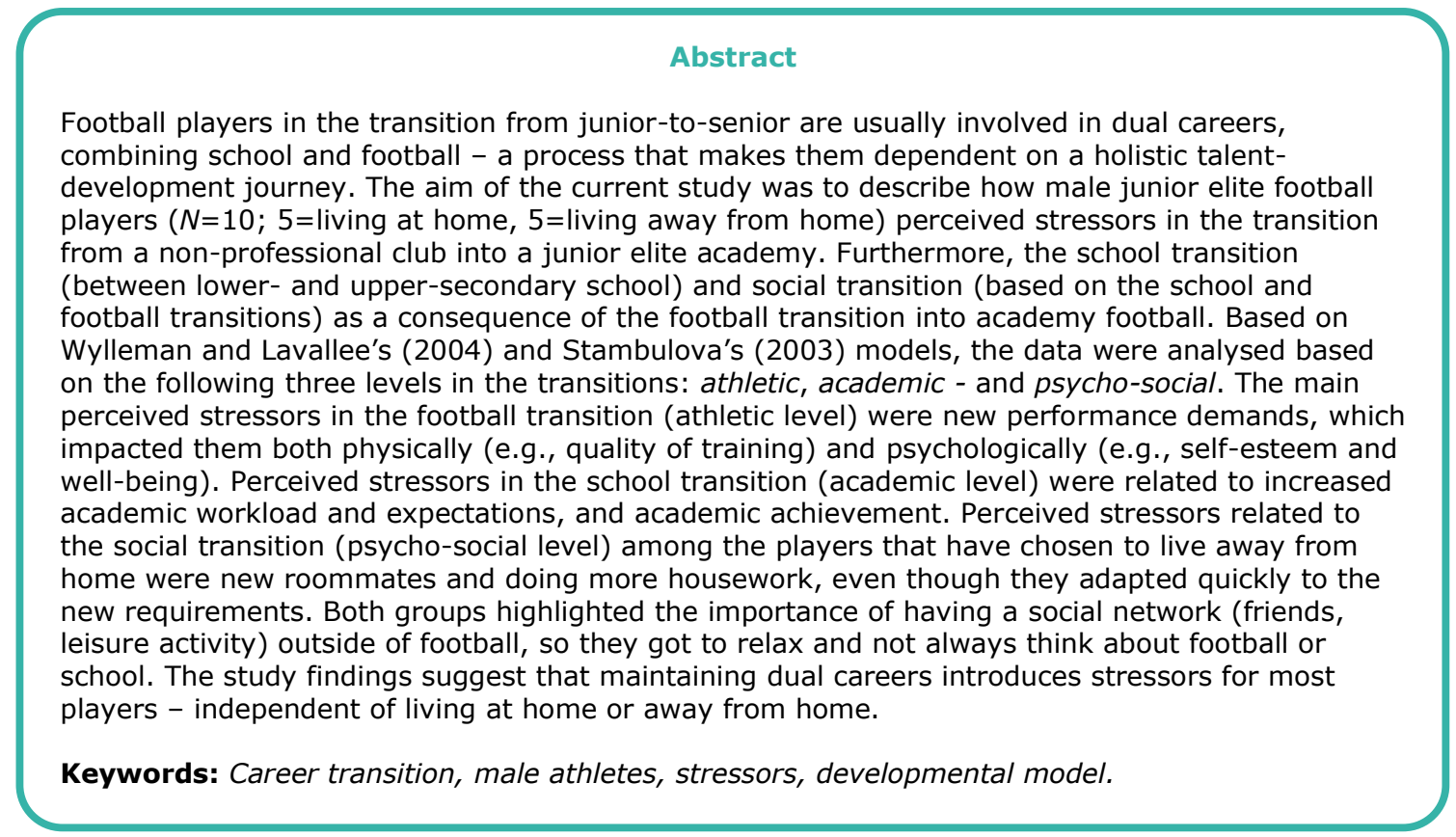

Football academies have been an essential part of talent development in European football, including the Scandinavian countries. When entering an academy, several transitions are apparent for many of the players: playing for a new team, starting at s new school and, for some players, accommodating to a new living environment (Nesti \& Sulley, 2015). Moreover, an integral part of an academy is internal team transitions (e.g., playing on different teams; U16 vs U19 team, also laying the foundation for the future junior-to-senior transition) (Morris et al., 2017). The oldest players in an academy are normally at the end of the upper secondary school and must balance the increased academic work and the football career (e.g., aiming at doing a dual career). All transitions and the balancing-acts between academic work and football are identified as significant stressors (Christensen \& Sørensen, 2009). Psychological stress is defined as 'a particular relationship between the person and the environment that is appraised by the person as taxing or exceeding his or her resources and endangering his or her well-being' (Lazarus \& Folkman, 1984, p. 19). Stressors occur during individuals' transactions with their environments and can be defined as 'environmental demands (i.e., stimuli) encountered by an individual' (Lazarus, 1999, p. 329). The talented players' perception of these stressors is important, and even more in a dual career perspective (Reeves et al., 2009). The competitive nature of attending a football academy at the age of 12-19 often includes stressors related to performance (fear of failure which has negative effect on team performance) and development (lack of selection, coach-athlete relationship) (Reeves et al., 2009; Sæther \& Aspvik, 2016; Sæther et al., 2017). In addition, unfulfilled demands and expectations related to school and social life outside the sporting context is related to stressors and decreased motivation and could subsequently contribute to decreased football development, burnout, and terminating the career (Goodger et al., 2007). From a talent development perspective, it seems to be advantageous if these transitions are normative (i.e., predictable), compared to 
non-normative (i.e., unpredictable), since the transition are challenging enough even when the players know what to expect (Wylleman \& Johnson, 2012; Wylleman \& Lavallee, 2004) and how they could receive support (Richardson et al., 2004).

\section{Theoretical approach}

According to Wylleman and Lavallee's (2004) development model, transitions can impact on an athlete's development within four domains: athletic, psychological, psychosocial, and academic/vocational. This model takes a career-long perspective, from initiation into sport at a young age, to termination of one's sporting career, and explains that athletes may experience overlaps between developmental layers at certain stages. Wylleman and Lavallee' (2004) highlight that although the stages and transitions that athletes may face at different levels of development have been described independently, one should take into account that they will generally occur in an interacting way. They furthermore stated: "Because sport psychologists should take a "holistic approach" to the study of transitions faced by athletes (Wylleman et al., 1999), a developmental model is proposed that (a) takes a "beginning-to-end" perspective and (b) reflect the development, as well as the interactive, nature of normative transitions at athletic, psychological, social, academic and vocational levels" (p. 519). The first of the four layers, the athletic, includes transitions such as i.e., into organized competitive sports at about 6 to 7 years old and into the highest or elite level at about 18 or 19 years of age. The second layer is about normative stages and transitions occurring at a psychological level such as i.e., development stages of childhood (up until 12 years of age) and adolescence (13 to 18 years). The third layer is about changes that can occur in the athlete's social development relative to her or his athletic involvement. While the fourth layer is about specific stages and transitions at academic and vocational level, from primary education at 6 or 7 years of age, to the potentially transition into higher education. However, in the model, it is also noted that some of the normative transitions may not occur, and thus, they become non-events, despite the athletes' wish to make the transition.

Stambulova $(2003,2009)$ considered in her Athletic Career Transition model that the transitions were a process of coping with a set of transition demands. Every transition is caused by a set of demands and was the effectiveness of coping with the demands depending on a dynamic balance between transition resources and barriers. Resources are internal or external features that assist coping, while barriers are internal or external features that restrict the coping process. The model further described two primary transition outcomes in either successful transition from effective coping with a good fit between resources and barriers and demands or a crisis transition where the coping is ineffective and good intervention is needed to find an exit. Depending on the intervention the athlete might proceed to successful but delayed transition outcome or to an unsuccessful transition which might lead to negative consequences ("costs") for the athlete.

\section{The context}

This study includes players from a Norwegian professional football club doing a dual career (both attending school and playing at a professional football club). In the current context, the players were on the move from the younger-than-19 age group squad to the senior team, where some of them were training and competing with senior players daily. Others (mostly the youngest) only sporadically were training with the senior team.
Occasionally, some of the players who just have moved up to senior football may still play with the youth team as preparation for eventually being consistently picked for the senior team in matches. The main focus of the study will be on the earlier transitions the players have done from a nonprofessional club into junior-elite football, both related to the athletic, academic and social-psychological levels, as a preparation to the junior-to-senior transition into elite football. Drew et al. (2019) earlier highlighted review of the junior-to-senior transition showed an increased number of studies within sports, mostly with the use of the theoretical approach of Stambulova $(2003,2009)$ and Wylleman and Lavallee (2004). Despite this, the focus on performance has been prominent (Reeves et al., 2009), and less on which stressors the players are faced with and how they impact their peer friendships, school performance, leisure activities, and overall wellbeing (Alfermann \& Stambulova, 2007).

Such dual careers within the Norwegian context most often mean attending a Sport Specific Programme (SSP), organised by the County Council in the region of the school. Such programmes are intended to help the athletes manage their dual career in the junior-to-senior transition. Despite their positive intentions and inclusion of talent development programmes (Kristiansen \& Houlihan, 2017), they often seem to increase the players physical and psychological loads (Wylleman \& Lavallee, 2004). Some coaches within these programmes have suggested that they can potentially destroy development in both football and school (Christensen \& Sørensen, 2009). An additional challenge is that players often need to travel or move to other parts of the county to attend an SSP; and often it also includes a club transfer (Kristiansen \& Houlihan, 2017). Leaving home at a young age means reducing their daily social support, especially from parents. Earlier research has highlighted the importance of parents on coping with pressure (Domingues \& Gonçalves, 2013), social support (Gledhill et al., 2017) and coping and stressor management (Dorsch, 2018). Even so, these SSPs are highly recommended by coaches, highlighting a coinciding development, making it lightly for players to choose such programs, the knowledge of how the athletes are affected (e.g., psychologically, and socially) by participating in these programs are quite scars (Kristiansen \& Houlihan, 2017), including how the players experience stressors as a consequence of their dual careers.

Based on Wylleman and Lavallee' (2004) and Stambulova (2003), the aim of the current study was to describe how male junior elite football players perceived stressors in the transition from a non-professional club into a junior elite academy. Furthermore, the school transition (between lower- and upper-secondary school) and social transition (based on the school and football transitions) as a consequence of the football transition into academy football.

\section{Methods}

\section{Participants}

The 10 male players interviewed were in transition from being youth football players to be full-time first team players at an elite professional football club. At the time of the interviews, they were aged between 17-19 years. The participants were players at the youth team and were recruited by representatives from the club's academy. To be included in this study, participants had to be contracted to play football for the club's academy and the players closest to being contracted by the club's first team according to one of the academy coaches in the club. An 
additional criterion was a balance in the sample in relation to living at home $(\mathrm{N}=5)$ and away from home $(\mathrm{N}=5)$.

\section{Interviews}

Semi-structured interviews were conducted by the first author and were based on previous theoretical framework (cf. Stambulova, 2003) and empirical literature on the junior-to-senior transition (e.g. Drew et al., 2019). The interview structure covered (a) introduction, (b) stressors, (c) living arrangements (d) school and leisure time and (e) summary. Interviews lasted between 28 and 36 minutes with an average of 32 minutes.

\section{Procedure}

After gaining ethical approval for the study (Norwegian Social Science Data Services), written consent was received from the manager of the club academy involved who gave permission for us to invite the ten players they highlighted as fulfilling the inclusion criterion to take part in the study. The players completed an informed consent form describing the study purposes, right to withdraw, risks, and safeguards, and confidentiality procedures. Then time was arranged for the face-to-face interviews where the participants were able to choose the locations of the interviews.

\section{Data Analysis}

The interviews were audio-recorded and all verbal talk transcribed. All players were given an identification (e.g., $\mathrm{P} 1, \mathrm{P} 2)$ to provide confidentiality. Using Wylleman and Lavallee's development model (2004) as a frame the data was analyzed based on the following, academic, athletic, and psychosocial levels. The data analysis is reported here through the six steps suggested by Braun et al. (2016) for thematic analysis in psychology: (1) transcribing, reading and re-reading the data; (2) generated initial codes; (3) deductive codes and identifying low-order themes; (4) outlining of the overall topics from the data in line with the three of the levels of Wylleman and Lavallee (2004); (5) reviewed and refined the subthemes and final categories (see Table 1); and (6) report-writing and presentation of data. Having gone through all the data from the interviews, we ended up with a set of topics related to the transitions: (a) football transition (athletic level), (b) school transition (academic level), and (c) social transition (psycho-social level).

\section{Results}

Table 1 presents the main findings of the data analysis in order to highlight the factors associated with the three transitions; (a) the football transition (athletic level) (b) the school transition (academic level) and (c) the social transition (psycho-social level).

\section{Football transition (athletic level)}

The transition from a non-professional football club into junior elite football and the increasingly competitive environment is characterized by higher performance level on parameters such as tempo/speed, competition playing time, and more training sessions. All players in this study experienced stressors in the transition, reporting that the new demands had an impact on their psychological wellbeing, self-esteem, worries, and nervousness:

'No, in the start I thought very much about impressing the coaches, so I became very simple. I didn't try to do anything special, just wanted to keep it simple so they didn't see any mistakes. But now that I've gotten into it a bit, I'm much better. I was a little tense at each training before'. P2
Another aspect was the change of clubs. Moving from their grassroots club, where they were playing with friends from early childhood, being one of the best players, to a new and professional club since they all were recruited to the professional club between the age of 14-16, new teammates and - for many of them, not being the best player in the squad - was a new, frightening and challenging experience:

'What was a bit strange was that you were among adults in the non-professional former club, and you would think that coming to a junior team here should be a pretty easy transition. But here it was much more technical, and it's more up to yourself here. At home, there were like ten seniors around you who looked after you well, but here it is more up to ourselves. So of course, you become much more independent. Here, in a way, you become one of many young talents.' $\mathrm{P} 1$

The players are entering a new environment where they are expected to perform and develop, and such expectation can be persistent stressors, and in periods of decreased performance or development these stressors could increase. Many of the players have experienced stressors, most often related to a lack of progress compared to other teammates as stated by $\mathrm{P} 1$ : 'There are twenty of us, and we are struggling to get up so it's clear that if you see someone on your side doing better than you, it's clear you feel stressed. You feel he is getting more attention'.

During hectic periods, the players have episodes of doubts in terms of going all in on a professional career. These doubts were naturally also present in periods when the players performed badly, in 'pre-season', at end of the season when there are many social gatherings as explained by P2: 'No, it's in adversity and when none of the shots are going in, or you get benched. Periods where I have don't score goals are heavy. Then I walked around thinking about whether I really want to continue'.

\section{School transitions (academic level)}

The school transitions from lower to upper secondary school were associated with increased academic workload and achievement pressure, (i.e., homework, test, and grades). The players response to the increased pressure was to become more structured and prioritise harder. The oldest players (finishing the upper secondary school) experienced this period as even more pressuring to make a dual career:

'Ehh, the biggest challenge might be priorities. (...) Planning so that you get the school done as well as possible, but at the same time have enough time to do football fully and put in the effort needed and all the training. And then I think it is very important to plan so that both parts can be completed as well as possible'. P7

The collaboration between the school and the club is closely related to the regulating of the training load. All participants reported that one of the coaches from the academy was also employed as a schoolteacher at the SSP, something they emphasised as vitally important when they for example were absent from school due to training camps or matches as explained by P2: 'That's very good. We have one from the club who also works at the school (..), if there are any matches when we have to travel, he will arrange all that, so we do not get any unnecessary absence'. The participants were, however, less satisfied with the organisation and facilitation of ordinary academic courses, which they all described as problematic at times as stated by P10: 'The teachers sometimes set up the schedule a little twisted, (...) It's hard to do well when setting up three 
or four tests at the same time. I am not that good at school. I am quite ordinary'.

Naturally, the players' perspective on the importance of school has an impact on their development. They highlight the importance of education, but they all admit that their school efforts and grades in periods are reduced because of football. The most important factor is that completing their education means that they have a safety net (in case their professional football career was terminated) as stated by P4: 'If you get injured, or don't become a professional then, or become a mediocre professional or what you might call it, then it is important to have studies as well so you can pick it up again later'.

During periods with high workload in both football and school, the players felt them to be competing arenas.
Two of the players clearly stated that these periods were challenging, but they often chosed to prioritize school, which negatively affected their self-organised training. High academic and training workload can cause fatigue, all participants stated that it negatively affected their concentration in school and training:

'If you have had a tough training period, then you are often tired. (...) You have to make sure you get enough sleep too ... when you are physically exhausted it can be difficult to concentrate at school, and I know that it can be for periods of time. So, I would say that getting tired is the biggest challenge. Both physically and mentally'. P8

\section{Main theme Higher order themes}

High level of competitors

Football transition

External pressure to perform among peers
Easy choice, but affected by friends Higher academic expectations

School transition
Higher inner and external pressure to perform Higher demands to prioritise and be structured

Worries about stagnation and future football career
Attending SSP

School and club collaboration

Trying the hardest
Well-coordinated training load

Bad academic coordination: period with high workload and pressure

Doubt about future professional football career

Balance act of doing double career
Leaving home

Social transition

Staying home

Support and friendship
Sacrifice for the dream

Tough start; boring, lack of support, practical challenges,

Positive ending; overcoming challenges, new friends,

Easy living, some parental nagging

Less time with friends and social gathering

Social support from my friends/family

Table 1: Main stress-related themes in the players school, football, and social transitions.

\section{Social transition (psycho-social level)}

One consequence of attending an SSP for half of the players in this study was moving away from their family home. This change - especially at the beginning - posed various feelings such as loneliness, the making a good first impression on roommates, preparing dinner and living with others:

'It was really boring in the beginning I have to say, because when you move you are not very good friends with the people you move in with and then there is a lot of time in the room. You don't know what they're thinking, I don't know if they like me. I'm a little more careful and just show the good side'. P2

New demands related to normal daily living activities such as shopping, making food, washing clothes, and get along new people was challenging. These stressors were naturally not apparent for players living with their parents, although they experienced problems, discussions and small conflicts with their parents as problematic.

When the players living away from their family home were asked about the situation today, they were all satisfied. The social aspect, joint interests, good relationships and being able to learn from each other, related to both football and life in general was highlighted as important.

'It's social, after all, you get to know the people you live with very well. So if you live with someone for two years, you get to know them incredibly well and you get a different friendship with them than the others on the team. Because you are with them and live with two and have four others close by. It builds very good relationships'. P4

The importance of every day social support from friends and teammates were described as important. Most players feel their friends accept that they prioritize football 
over social events, even though some of the players had experienced that their choice not always was welcome. Related to their teammates, one of the players (P5) highlighted that they motivate each other to undertake selforganised training sessions, and in general push each other to become better players: 'You learn something from others (...), and you can also talk a bit about football and what others can improve on. You see weaknesses and strengths for each other then'.

The players who chose to live at home experienced the transition to a new school as easier than the players who moved out, mostly because they knew other people, both players and non-players, attending the same school, and the non-players helped them think of other things than football. P9 described this as such: 'I think that is incredibly important really. It's tough sometimes, with playing time and stuff. But friends from outside make you .. not relax .. but just chill, and find something else to think about every now and then'.

The players in this study felt they had scarified something to be where they are, such as moving away from family, or social aspects, but even so they feel it has been worth it:

'Yes, you sacrifice a lot socially then. There are many parties to miss. Many things with friends that you can't join in with, because we travel a lot on weekends. But I get time to what I want to do, and I don't feel sacrificed even if I don't go to a party, because it's a football player I want to be, and then I go all out for that'. P8

\section{Discussion}

The aim of the current study was to describe how male junior elite football players perceived stressors in the transition from a non-professional club into a junior elite academy. Furthermore, the school and social transitions as a consequence of the transition into academy football. In this study we focused on players in the transition from a non-professional club into a junior elite academy and thereby the preparation to the junior-to-senior-transition, while earlier research mostly has studied the junior-tosenior-transition.

All players considered their aim towards a dual career as challenging because they considered the normative stressors as more intense, of longer duration and at a higher frequency in terms of academic and performance pressure. Related to the football transition the players experienced an increased amount of sporting stressors such as a higher intensity in the training sessions, a higher training load, and competition on team selection, which again lead to a psychological impact in form of tension and uncertainty. Confirming earlier research on the junior-to-senior transition (Drew et al., 2019), our findings highlight that the players go from being superior in their teams to being inferior related to performance. Even though their club change is a natural consequence of ambitions as football players, they still experience stressors related to this transition.

Despite the most often reasoning of choosing an SSP is the better adjustment of their dual career through better training and particularly regulating of the training load, the players experience in their school transition periods of weak sport-school adjustments especially related to ordinary academic courses, resulting in an increased academic pressure making it more difficult to achieve good grades (Goodger et al., 2007). Part of the reasoning for prioritising school as many of the players claimed to do, also partly explaining their down prioritising of selforganised training sessions. The players therefore considered education as a safety net (Aquilina, 2013), if they did not make it into professional football. This could perhaps also be the reason why every second player actually experienced periods where they doubted their decision to go all in on football. This was especially evident in periods where they experienced stressors related to both school and football, where they felt they was competing arenas (Christensen \& Sørensen, 2009).

Even though players considered both parents and friends as important in their social transition, they described their parents' involvement important for both school and football, but not by introducing pressure, which has been the case in other studies (Dorsch, 2018; Gould et al., 1997). In periods of doubt related to their football career, social support from parents or friends (Gledhill et al., 2017; Van-Yperen \& Duda, 1999) was described as very important. This was in the beginning especially task and social stressors for players living away from home, which they, however, adapted to quite quickly. The results even indicate that the players living away from home get a social network of socially supporting roommates being in the same situation as themselves who they could discuss issues related to their development as footballers.

Undertaking dual careers could be an arena for mastery since both arenas could have their stressors at times but give the players the opportunity to have different arenas to master in different periods. By making effort both related to football and school, they could build selfconfidence and develop a base for handling stressors related to their identity as being both a footballer and a pupil (Nesti \& Sulley, 2015). Since most players made an effort with schoolwork, the players in this sample felt they must prioritise and structure their time to be able to conduct dual careers. The oldest players particularly emphasised that they were in a period where they felt pressure on time, especially related to schoolwork, since they are at the end of their upper secondary school education, confirming earlier studies (Christensen \& Sørensen, 2009).

\section{Methodological reflections and limitations}

The current findings must be considered in light of its strengths and limitations. The study is theoretically based on Stambulova's (2003, 2009) and Wylleman and Lavallee's (2004) works that give a strong theoretical base for the study. Wylleman (2019) has however, introduced a new Holistic Athletic Career Model, but unfortunately this model was developed and elaborated (i.e., published) after the data sampling in this project was done. Thus, we will recommend that model as the departure model for further studies. Nevertheless, the strength in the present study was our sample where many of the players partly both train and compete with the professional senior players in the club, while others are preparing for the junior-to-senior transition in the same club - and, as such, an especially relevant sample to get the players' perceptions of this transition. Despite the fact that all our participants came from the same professional football club, the transferability (Smith, 2018) of the project is high, especially to other professional football clubs, but also athletes in other sports in the junior-to-senior transition. Furthermore, we would also argue that the study could be related to an analytical generalization through a theoretical generalization since the two theoretical approaches used in the study are well established.

\section{Practical implications}

This study has addressed some of the stressors talented football players experience in the junior-to-senior 
transition. The players' experience should be taken into consideration by both coaches in professional football academies and teachers in upper secondary school. Despite the efforts from both these actors, the players experience the stressors as impacting their development, partly because of lack of adjustments between these two "worlds". The players are a part of both of them, and even if the transition is challenging in itself, they need help to overcome their everyday stressors in this transition. In order to support the athletes in the development process, a close coach-athlete relationship (Jowette \& Lavallee, 2007) and continues individual coaching conversations (Høigaard \& Jørgensen, 2007) is recommended.

\section{Conclusion}

The main perceived stressors in the football transition (athletic level) were new performance demands, which impacted the players both psychologically (i.e., selfesteem and well-being), and their development process (i.e., fear of doing mistakes and lack of progress and development). These factors had especially impact in periods of doubt about whether the persons would continue their pursuit of a professional football career. Stressors in the school transition (academic level) were increased academic workload and performance level, also described as importance since the athletes at least partly prioritized school as it was considered a safety net. In addition to the increased demands in football and school domain, they also become competing arenas which add additional stress for the players. Related to the social stressors the players living away from home experienced more stressors related to getting new roommates and doing housework, which they quickly adapted to. The players living away from home did, however, also get social support from their roommates which they described as having a positive impact on their development as footballers. Both groups described the importance of having a social network (friends, leisure activity) outside of football, so they got to relax and don't always think about football or school. The study findings suggest that maintaining dual careers introduces stressors for most players - independent of living at home or away from home.

Disclosure statement

No potential conflicts of interest were reported by the authors.

\section{References}

Alfermann, D., \& Stambulova, N. (2007). Career transitions and career termination. In G. Tenenbaum, \& R. C. Eklund (Eds.), Handbook of sport psychology (3rd ed., pp. 712-736). Wiley.

Aquilina, D. (2013). A study of the relationship between elite athletes' educational development and sporting performance. The International Journal of the History of Sport, 30(4), 374-392.

Braun, V., Clarke, V., \& Wheate, P. (2016). Using thematic analysis in sport and exercise research. In B. Smith, \& A. Sparkes (Eds.), Routledge handbook of qualitative research in sport and exercise (pp. 191-205). Routledge.

Christensen, M. K., \& Sørensen, J. K. (2009). Sport or school? Dreams and dilemmas for talented young Danish football players. European Physical Education Review, 15(1), 115-133.

Domingues, M., \& Gonçalves, C. E. (2013). The role of parents in talented youth sport. Does context matter? Polish Journal of Sport and Tourism, 20(2), 117-122.

Dorsch, T. E. (2018). Optimising family involvement in youth sport. In C. J. Knight, C. G. Harwood, \& D. Gould (Eds.), Sport psychology for youth athletes (pp. 106-115). Routledge.

Drew, K., Morris, R., Tod, D., \& Eubank, M. (2019). A meta-study of qualitative research on the junior-to-senior transition in sport. Psychology of Sport and Exercise, 45. https://doi.org/10.1016/j.psychsport.2019.101556

Gledhill, A., Harwood, C., \& Forsdyke, D. (2017). Psychosocial factors associated with talent development in football: A systematic review. Psychology of Sport and Exercise, 31, 93-112.

Goodger, K., Gorely, T., Lavallee, D., \& Harwood, C. (2007). Burnout in sport: A systematic review. The Sport Psychologist, 21(2), 127-151.

Høigaard, R. \& Jørgensen, A. (2007). Coaching conversations. A way of fostering athletes to peak performance. Olympic Coach, 19(3), 4-7.

Jowette, S., \& Lavallee, D. (Eds.). (2007). Social Psychology in Sport. Human Kinetics.

Kristiansen, E., \& Houlihan, B. (2017). Developing young athletes: The role of private sport schools in the Norwegian sport system. International Review for the Sociology of Sport, 52(4), 447-469.

Lazarus, R. S. (1999). Stress and emotion: A new synthesis. Springer.
Lazarus, R. S., \& Folkman, S. (1984). Stress, appraisal, and coping. Springer.

Morris, R., Tod, D. \& Eubank, M. (2017). From youth team to first team: An investigation into the transition experience of young professional athletes in football. International Journal of Sport and Exercise Psychology, 15(5).523-539.

Nesti, M., \& Sulley, C. (2015). Youth development in football. Lessons from the world's best academies. Routledge.

Reeves, C. W., Nicholls, A. R., \& McKenna, J. (2009) Stressors and coping strategies among early and middle adolescent premier league academy soccer players: Differences according to age. Journal of Applied Sport Psychology, 21(1), 31-48.

Richardson, D., Gilbourne, D., \& Littlewood, M. (2004). Developing support mechanisms for elite young players in a professional soccer academy: Creative reflections in action research. European Sport Management Quarterly, 4(4), 195-214.

Smith, B. (2018). Generalizability in qualitative research: misunderstandings, opportunities and recommendations for the sport and exercise sciences. Qualitative Research in Sport, Exercise and Health, 10(1), 137-149,

Stambulova, N. B. (2003). Symptoms of a crisistransition: A grounded theory study. In N. Hassmen (Ed.), Svensk Idrottspykologisk Förening (pp. 97-109). Örebro University Press.

Stambulova, N. (2009). Talent development in sport: A career transitions perspective. In E. Tsung-Min Hung, R. Lidor, \& D. Hackfort (Eds.), Psychology of sport excellence (pp. 63-74). Fitness Information Technology.

Sæther, S. A., \& Aspvik, N. P. (2016). Norwegian junior football players - player's perception of stress according to playing time. Sport Science Review, 1-2, 85-96.

Sæther, S. A., Aspvik, N. P., \& Høigaard, R. (2017). Norwegian football academy players - players' characteristics, stress and coach-athlete relationship. The Open Sports Sciences Journal, 10, 141-150.

Wylleman, P., \& Johnson, U. (2012). Sport psychology and the Olympic Games: An introduction in the special issue. Psychology of Sport and Exercise, 13(5), 658-659.

Wylleman, P., Lavallee, D. \& Alfermann, D. (1999). Transitions in the career of competitive athletes. Lund, Sweden: FEPSAC. 
Wylleman, P., \& Lavallee, D. (2004). A developmental perspective on transitions faced by athletes. In $M$. Weiss (Ed.), Developmental sport psychology (pp. 507-527). Fitness Information Technology.

Wylleman, P. (2019). A developmental and holistic perspective on transiting out of elite sport. In $\mathrm{M} . \mathrm{H}$. Anshel, T. A. Petrie, \& J. A. Steinfeldt (Eds.), APA handbooks in psychology series. APA handbook of sport and exercise psychology, (pp. 201-216). American Psychological Association. 